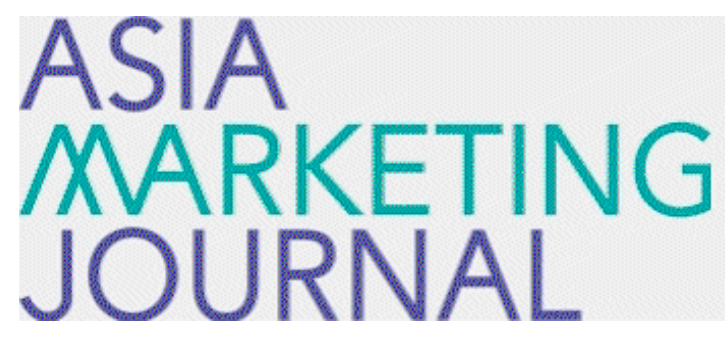

ASIA MARKETING JOURNAL

Volume 20 | Issue 3

Article 3

$10-31-2018$

\title{
Exploring Consumers' Alcoholic-Beverage Type-Specific Drinking Motives
}

Hyejeung Cho

Follow this and additional works at: https://amj.kma.re.kr/journal

Part of the Marketing Commons

\section{Recommended Citation}

Cho, Hyejeung (2018) "Exploring Consumers' Alcoholic-Beverage Type-Specific Drinking Motives," Asia Marketing Journal: Vol. 20 : Iss. 3 , Article 3.

Available at: https://doi.org/10.15830/amj.2018.20.3.39

This Article is brought to you for free and open access by Asia Marketing Journal. It has been accepted for inclusion in Asia Marketing Journal by an authorized editor of Asia Marketing Journal. 


\section{Exploring Consumers' Alcoholic-Beverage Type-Specific Drinking Motives: The Case of Young Adult Females in South Korea}

Hyejeung Cho*

Despite the abundance of research on alcoholic-beverage consumption in the food and beverage marketing literature, research directly assessing and comparing consumers' psychological motives for drinking different types of alcoholic beverages is relatively limited. There is also a paucity of research comparing drink-type specific consumption motivations in an Asian market. Paying attention to some recent new changes in the alcoholic-beverages market of South Korea, this study investigated South Korean young adult female consumers' alcoholic-beverage type-specific drinking motives. A self-administered online survey of 340 young adult female drinkers about their alcohol-consumption patterns, alcoholic-drink preferences, involvement with alcohol, and four types of drinking motives (coping, social, conformity, and enhancement motives) revealed differences in: (1) the association between the consumer's alcohol involvement level, alcohol consumption frequency/amount, and preferences for alcoholic beverages across different types of alcoholic drinks; (2) the underlying psychological motives for drinking different types of alcoholic beverages; (3) the association between consumption contexts and alcoholic drink types; and (4) the consumption patterns and drinking motives across different consumer groups that are segmented in terms of their most preferred type of alcoholic beverages. These findings point to the importance of investigating drink-type-specific consumption motivations in alcoholic-beverage consumption research. Limitations and implications for future research are also discussed.

Key words: Alcoholic beverages, Drinking motives, Young adult females, Consumer preferences, Involvement

\footnotetext{
* Department of Business Administration, Ewha Womans University(hj_cho@ewha.ac.kr)
} 


\section{Introduction}

In the literature on food and beverage consumption, many studies investigated consumers' alcohol-consumption patterns, various productintrinsic and extrinsic factors that influence consumer perceptions and choices of alcoholic drinks, and numerous cultural, sociodemographic, and psychological factors that are associated with alcohol consumption (e.g., Balestrini \& Gamble, 2006; Cardello et al., 2016; Corduas, Cinquanta, \& Ievoli, 2013; Muggah \& McSweeney, 2017; Pomarici et al., 2017; Silva et al., 2016). However, despite the abundance of research on alcoholic-beverage consumption, the research that specifically addresses consumers' psychological motives for alcohol consumption is relatively limited. In addition, because many of the studies dealing with consumer motivations for drinking have been conducted in Western countries focusing on wine consumption (e.g., Charters \& Pettigrew, 2008; Olsen, Atkin, \& Thach, 2016: Palma et al., 2014; Somogyi et al., 2011), there is also a paucity of research that investigates motivations underlying a consumer's choice of various alcoholic-beverage types. People's psychological needs for consuming alcohols are multi-dimensional (e.g., Cooper, 1994), and therefore different types of alcoholic drinks are likely to serve different types of needs. Hence, the aim of this paper is to explore and demonstrate how different types of alcoholic beverages serve various psychological needs (e.g., social, coping, conformity, and enhancement motives) that consumers have. This study also aims to explore whether and how the patterns of association between specific drink types and underlying consumption motives differ across drinker groups when consumers are segmented on the basis of their drink-type preferences. In specific, the study addresses these research questions by focusing on young adult females in South Korea, one of the major geographical segments in the Asian alcoholic-beverage market.

South Korea, where drinking has traditionally been an important communal activity, is now going through some new social and cultural transitions as more and more people are living alone and spending time alone. For example, over the recent few years, the new cultural trend of "solo" consumption (e.g., solo travel, solo dining) has noticeably risen among young adult consumers in their 20s and 30s (Jackson, 2017). With the rise of solo consumption, the number of people who drink alone or at home has also significantly increased. In line with this new cultural trend, convenience stores have emerged as a major distribution channel for alcoholic-beverage products, the imported beer market has sharply grown posing a new threat to domestic beer brands, and the market for flavored lower-alcohol drinks, mainly targeting young adult female drinkers, has also emerged (Jang, 2017; Kim, 2018). Consumers in South Korea now appear to have many more choices 
than before when it comes to what alcoholic beverage to drink.

Paying attention to these new changes, this study investigated young adult female consumers' alcoholic-beverage type-specific drinking motives based on the four-factor model of drinking motivations (Cooper, 1994). As mentioned earlier, this research aims to fill the gaps in the relevant literature by quantitatively assessing and comparing drink type-specific consumption motives and also by adding to the understanding of young adult female consumers' drinking motivations in South Korea where only limited research has been done. The remainder of this paper is structured as follows. The next section presents a brief review of the relevant literature on alcoholic-drink consumption motivations. The third section provides an overview of South Korean drinking culture and its alcoholicbeverages market. Then the next two sections explain the methodology used and the findings respectively. Finally, the last section concludes with a discussion of the implications of the study and directions for future research.

\section{Research Background}

\subsection{Motivations for Alcoholic-Beverage Consumption}

Consumption motivation has long been an important subject of interest for consumer researchers in food marketing because it closely relates to consumers' attitudes, expectations, and preferences. For alcoholic beverages, several research studies have explored various cultural, sociodemographic, and lifestyle characteristics of consumers and important product-related factors that influence consumer perceptions and choices (e.g., Cardello et al., 2016; Corduas, Cinquanta, \& Ievoli, 2013; Silva et al., 2016; Thong, Thanh, Solgaard, \& Yang, 2017). For example, Corduas, Cinquanta, and Ievoli (2013) investigated Italian consumers' wine perception and found that the importance of wine attributes depended on expertise, purchase place and consumption occasions. Bruwer, Chrysochou, and Lesschaeve (2017) reported that the most important choice attribute for Canadian winedrinkers was wine style, followed by grape variety and price. They also grouped product choice factors into extrinsic cues, intrinsic cues and marketing mix factors and examined how consumer involvement and product knowledge influenced the importance of those factors. In the beer consumption domain, Muggah and McSweeney (2017) investigated female Canadian consumers' preferences for beer attributes (e.g., taste, style of beer, packaging, color, brand) and discovered that flavor, followed by beer style, appearance and brand, was the most important attribute driving consumer liking. Although these studies did not directly address motivations, they provide insights into why people drink and what they look for when 
making consumption decisions about alcoholic beverages. There are also some alcoholic-beverage consumer studies that more directly dealt with motivations. For example, Charters and Pettigrew (2008) discovered that experiential motivations (e.g., hedonic enjoyment from taste and food pairing) were strongly associated with Australian consumers' wine consumption, followed by symbolic motivations (e.g., rituals, self-image). Somogyi et al. (2011) discovered that Chinese consumers were primarily influenced by face and status in their wine consumption because of the symbolism of wine (i.e., perceived as socially and culturally sophisticated). In terms of market segmentation, Olsen, Atkin, and Thach (2016) proposed a wine-market segmentation approach based on ten universal values of life (Schwartz, 2012) and identified four groups of wine consumers that are oriented toward the values of self-enhancement, conservatism, selftranscendence, and openness to change. In a similar context, Palma et al. (2014) proposed motivational factors that can be used for segmenting wine consumers: social cohesion, sophistication, self-indulgence, and tradition. They further noted that multiple motivations can be present for the same consumer as the person faces different consuming occasions. These studies have provided important insights into the psychological motivations underlying alcohol consumptions, but at the same time they are mostly limited to the domain of wine consumption.

Some other studies have compared consumption motivations associated with different types of alcoholic drinks. For example, Chrysochou (2014) investigated consumer preferences for light beer and found that health concern was an important underlying motive for choosing light beer as opposed to regular beer in Iceland. Similarly, for beer, Gómez-Corona et al. (2016) explored Mexican consumers' motivations associated with craft vs. industrial beer consumption. They found that, unlike industrial beer, craft beer was perceived more as an experience-based and symbolic product than as a utilitarian one, as well as that the main motivation for drinking craft beer was the quest for authenticity. Also, according to a recent review of studies concerning wine, beer, and non-alcoholic beer consumption in Portugal and the Netherlands (Silva et al., 2017), wine and beer are not only perceived to have different functional connotations (e.g., wine as a social facilitator vs. beer as a thirst quencher) but also associated with different kinds of emotions and feelings. Taken together, these studies offer important findings and implications that psychological motivations for consuming alcoholic beverages can significantly differ for specific drink types and drinking situations.

The present study adds to this line of research by investigating the similarities and differences in the consumption motivations associated with different types of alcoholic beverages. Given that many of the prior studies that explored differences in drinking motivations associated 
with different types of alcoholic drinks have taken qualitative research approaches, this study aims to contribute to the relevant literature by using a quantitative research method in assessing and comparing psychological motivations for drinking. Specifically, our assessment of motivation is based on the four-factor model of drinking motivation proposed by Cooper (1994). Cox and Klinger (1988) had proposed a conceptual characterization of drinking motives according to the valence (positive or negative) and source (internal or external) of the outcomes individuals expect to achieve by drinking. Crossing these two dimensions, Cooper (1994) proposed a model consisting of four categories of motives: drinking to increase positive mood or well-being (positive, internal; labeled "enhancement" motives), drinking to obtain social rewards or benefits (positive, external; "social" motives), drinking to cope with negative emotions (negative, internal; "coping" motives), and drinking to avoid social censure or rejection (negative, external; "conformity" motives). This model has been frequently used in health research, for example, in the investigation of alcohol-consumption behavior of adolescents and young adult populations. However, because typically health research on alcohol consumption is interested in the why of drinking (as opposed to not drinking), the assessment of drinking motivation using this model has mostly focused on the general act of drinking.

Only a few studies have taken specific beverage types into account. For example, Kuntsche,
Knibbe, Gmel, \& Engels (2006) investigated whether drinking motives modify the association between adolescents' alcoholic-beverage preference and their alcohol use. In their study, enhancement motives were found to be positively related to Switzerland adolescents' consumption of beer and spirits and negatively to their consumption of wine and alcopops. Social motives were positively related to the consumption of alcopops and negatively to the consumption of wine. In a similar context, Graziano et al. (2012) investigated the associations between Italian adolescents' drinking motives and how much they drank of specific types of beverages. Their study revealed that coping motives were positively related to the Italian adolescents' high consumption of all types of alcoholic beverages, whereas conformity motives were negatively related to high beer consumption. These studies provide additional insights into alcohol-consumption motivations by revealing different association patterns between drinking motivations and what specific types of drinks are consumed more or less. Nonetheless, the implications from those studies for consumer and marketing researchers are limited because they focused on adolescents' drinking in health research contexts. Also, the studies measured people's motivations for general drinking rather than assessing drinking motivations for different types of drinks. Unlike the above-mentioned studies, the present study explores consumers' beverage-specific drinking motivations by assessing drinking motivations 
for each type of alcoholic beverage separately. In specific, this study assesses how frequently a person consumes a particular type of alcoholic drink for coping, social, conformity, and enhancement-related reasons. As noted earlier, alcoholic-beverage consumption motivations can significantly differ across countries and cultures (e.g., Kuntsche et al., 2006) but there is little research on Asian markets in the relevant literature. Hence, this study also aims to fill the gap by adding research findings from South Korea.

\subsection{Alcoholic-Beverage Market and Drinking Culture of South Korea}

South Korea is one of the major geographical segments in the Asian alcoholic-beverage market. According to the World Health Organization (2014), the global average of alcohol consumption is 6.2 liters per person per year. South Korea (referred to hereafter as Korea) is one of the top 15 countries in the global alcoholic-beverage market, with an average of 12.3 liters of alcohol consumed per capita per year. Korea is also known for drinking the largest amount of hard liquor in the world, primarily because of Koreans' heavy consumption of Soju, a clear vodka-like distilled spirit with an alcohol content of about $20 \%$. Because of its low price, wide accessibility, and neutral taste that goes well with many Korean dishes, soju has led the Korean alcoholicbeverage market for many decades, along with beer. According to a recent industry report by the Korea Agro-Fisheries \& Food Trade Corporation (2016), soju and beer accounted for about $28 \%$ and $52 \%$, respectively, of the total retail sales of alcoholic beverages in Korea as of 2014, and Korean adults consumed an average of 65 bottles of soju and 148 bottles of beer the same year. Korea's heavy drinking pattern is often linked to the role of drinking as an outlet for relieving stress, because Korea is known for a quite rigid hierarchy at workplaces and long working hours compared to many other countries (Çakar \& Kim, 2015). At the same time, because it also helps people to relax and open up, drinking has long been considered important for building and maintaining a good relationship with others (Kim \& Hong, 2012). Drinking is commonly expected at many social and business occasions in Korea. Workers very often go out in a group with their $\mathrm{co}^{-}$ workers to have drinks together for informal bonding (Kim \& Rhee, 2014), and university students consider drinking with peers a very important part of their social life (Yang, 2015). Korea's strong communal drinking culture and its adoration for the national spirit (soju) are likely to remain stable over the years to come, because they are deeply rooted in the country's social structure, traditions, and lifestyles.

Recently, there have been some notable new trends in the Korean alcoholic-beverages market. One big trend is the sharp growth of imported beer with a rise of single-person households 
and the "solo" drinking culture. Shaking up the domestic beer industry, which has long been dominated by two leading Korean breweries (Oriental Brewery and HiteJinro), Korea's beer imports have more than tripled over the past five years and hit the record high of $\$ 263$ million in 2017, up 250\% from 2012 (Korea Customs Service, 2018). Although domestic beer still accounts for a majority of beer sales in Korea, the emerging presence of imported beer brands is posing new threats to Korean beer companies as the rapid growth of the imported beer market is expected to continue, whereas the sales of domestic beer are expected to remain stagnant or gradually decrease (Global Agriculture Information Network, 2018). Several factors have contributed to the growing popularity of imported beer in Korea. One is the improved price competitiveness of imported beers, particularly the ones from Europe and the U.S., because of the gradual reductions of import tariffs. Another factor has to do with consumers' growing demand for a diversity of beers, which has not been well served by the local Korean beers because they tend to be homogeneous in styles, being mostly pale lagers, and tastes (Sohn, 2016). With allegedly more than 600 foreign beer products available in the market, Korean consumers now have many more choices to explore than ever (Jang, 2017). Another reason for the popularity of imported beer is linked to the new trend of "solo" consumption which has lately grown among the generation in their 20s and 30s. As stated earlier, frequent and heavy communal drinking in a social context has long been a strong characteristic of the Korean drinking culture. However, with the rise of single-person households who enjoy at-home entertainment, the number of consumers in their 20s and 30s who enjoy at-home drinking alone has also grown, boosting imported beer sales in retail chains, such as convenient stores and hypermarkets, where imported beer now accounts for more than $50 \%$ of beer sales (Kim, 2018).

Another noticeable change in the alcoholicdrink market of Korea is the growing demand of the younger generation for more flavorful low-alcohol-content drinks. Fruit-flavored lowalcohol soju ("flavored soju") and flavored alcoholic sodas ("alcopops") are the representative types of flavored alcoholic-beverages that have recently gained popularity among the young consumers, particularly young women, in Korea (Jang, 2015). The flavored soju is a sweet and mild variant of the regular soju (about 5-7\% lower in alcohol content than soju). As for the alcopops, unlike some other countries (e.g., Australia, the U.K., the U.S.) where alcopops or other similar flavored low-alcohol-content products (with 3-5\% alcohol content) have already emerged as a new category of alcoholic beverages as early as the 1980s (Mosher, 2005), alcopop products started to gain popularity in Korea recently. 


\subsection{Research Questions}

To summarize, this study aims to contribute to the literature by exploring how different types of alcoholic beverages serve consumers' various psychological needs (e.g., social, coping, conformity, and enhancement motives) and investigating how the patterns of association between drink types and underlying consumption motives differ across drinker groups when consumers are segmented on the basis of their drink-type preferences. This study also aims to fill the gap in the literature where relatively little research has been done in Asian markets regarding consumers' psychological motivations for drinking. In particular, this study intends to help expand our knowledge about young female consumers' alcohol-consumption patterns and underlying motivations in Korea. Because the Korean alcoholic-beverage market is now quickly being diversified, it would be meaningful to see how different types of alcoholic drinks serve consumers' needs in terms of their psychological motives for consumption. This study focuses on discovering the patterns of consumption and underlying motives associated with the drinks that have recently gained much popularity among young adult female consumers, such as imported beer, flavored soju, and alcopops, in comparison with domestic beer and regular soju, the two most typical drinks that have long been associated with social drinking in Korea. Based on the four- factor motivational model of drinking (Cooper, 1994; Cox \& Klinger, 1988) and using a survey of young female adults in Korea, we will identify (a) young female consumers' preferences for various alcoholic-drink types, (b) how their consumption motives differ with different types of alcoholic drinks, (c) how their contextual consumption patterns (e.g., drinking location, companions) differ for different types of drinks, and (d) how the patterns of association between drink types and consumption motives differ across drinker groups that are segmented based on drink-type preferences.

\section{Methods}

\subsection{Survey Sample}

The study sample consisted of 340 university students (all females) in Seoul, Korea, who had consumed alcoholic beverages at least once during the 30 days before their participation in this study. The legal drinking age in Korea is 19, and all of the participants were aged 19-26 ( mean age $=21.21, \mathrm{SD}=1.53$ ). . Participants completed an anonymous online self-report survey questionnaire about their alcoholicbeverage consumption. 


\subsection{Measures}

\subsubsection{Drinking frequency and quantity}

The frequency of alcohol drinking was assessed by asking, "How often (i.e., how many drinking occasions) in the past 30 days have you consumed alcoholic drinks?" Response options were ' 0 ', ' 1 ', '2, ' '3, $\cdots$, and ' 10 or more'. The response option ' 0 " was used for screening (i.e., those who chose ' 0 ' were led to the end page of the survey to exit). The amount of drinking was measured by two separate questions assessing participants' usual drinking amount of beer and soju, the two most commonly consumed types of alcoholic beverages in Korea. Participants were asked to indicate the usual amount of beer they drank on an ordinary occasion of drinking (if they were to drink beer only) and also indicate the usual amount of soju they drank on an ordinary occasion of drinking (if they were to drink soju only). For the beer amount question, response options ranged from ' 1 can $(350 \mathrm{ml})$ of beer' through 'more than five cans of beer'. When they chose the latter, they were prompted to write the specific number of cans or the amount in ml. For those who did not drink beer, the response options also included 'I do not drink beer.' For the soju amount question, response options ranged from '1-2 shots' through 'more than 12 shots (about 1.5 bottles)'. Respondents who picked more than 12 shots were asked to indicate the specific amount in the number of shots or bottles. The response options also included 'I do not drink soju'.

\subsubsection{Alcoholic drink preference}

Consumers' drink preferences were assessed based on their frequency of consumption. Respondents were shown a list of various alcoholic drinks (domestic beer, imported beer, regular soju, flavored soju, alcopops, and others) with a short explanation of each type and asked to think about how often they consumed those drinks. Then they were asked to rankorder the drink types based on their frequency of consumption ( 1 = drink the most frequently; $7=$ drink the least frequently). This information was used later for segmenting drinker types, that is, based on the most frequently consumed ("preferred") type of drink.

\subsubsection{Drink-specific consumption motives}

Participants' drink-type-specific consumption motives were measured using the 16-item drinking-motive questionnaire developed by Shin and Han (1999) based on the four-factor model (Cooper, 1994). The 16 items represent four categories of drinking motives: coping (4 items; e.g., "because it helps me when I feel sad"), social (4 items; e.g., "because it makes a social gathering more enjoyable"), conformity (4 items; e.g., "because I don't want to feel 
left out"), and enhancement motives (4 items: e.g., "because it reduces boredom and makes me feel refreshed”). Respondents' drinking motives were measured for each of the five focal drink types separately: domestic beer, imported beer, regular soju, flavored soju, and alcopops. For each drink type, participants were instructed to indicate how often they had consumed the target drink type in the past three months for each given motive stated in the questionnaire, using a 5-point scale (1 = never; 5 = almost always). The internal reliability coefficients (Cronbach's alpha) were 0.95 (coping motive), 0.96 (social motive), 0.92 (conformity motive), and 0.91 (enhancement motive). The subscale internal consistencies reported in Shin and Han (1999) ranged from 0.81 (social) to 0.93 (coping).

\subsubsection{Drinking contexts}

To assess the association between alcoholicdrink types and drinking contexts, participants were asked to indicate how often $(1=$ never; 5 = almost always) they consumed each drink type when they drank alone, drank with friends, and drank with family. Participants were also asked to indicate which type of alcoholic drinks they drank (or purchased) most frequently when they drank at home, drank at a restaurant, drank at a bar, or purchased at a convenience store.

\subsubsection{Alcohol involvement}

Alcohol involvement was measured using a 7-item scale adapted from Zaichkowsky's Personal Involvement Inventory (1985, p. 342), which deals with "a person's perceived relevance of the object based on inherent needs, values, and interests". The scale used in this study included items such as "I am interested in alcoholic drinks", "Alcoholic drinks are valuable to me", "Alcoholic drinks are appealing to me", and "Alcoholic drinks are important to me" (1 = fully disagree; 5 = fully agree).

\section{Results}

\subsection{Alcoholic-Beverage Preference}

For the drink preferences, 92 out of 340 (27.1\%) respondents indicated that they had consumed imported beer, out of all the types, most frequently in the past 30 days. In the present study, these consumers are called the “imported beer-preferring group”. Domestic beer, flavored soju, regular soju, and alcopops were picked as the most frequently consumed alcohol-drink type by 65 ("domestic beerpreferring group"), 65 ("flavored soju-preferring group”), 61 (“soju-preferring group”), and 51 ("alcopops-preferring group") respondents, respectively. Six respondents preferred other 
types of drinks and they were excluded from the subsequent data analyses.

\subsection{Drinking Patterns, Involvement, and Group Differences}

For the frequency of drinking, 47.6\% of the 334 respondents had 1-3 drinking occasions, 30.5\% had 4-6 drinking occasions, and 21.9\% had 7 or more drinking occasions in the preceding 30 days (median $=4$ occasions $/$ month). For the drinking quantity, 295 respondents (excluding 39 respondents who did not drink beer) indicated that they drank an average amount of $780 \mathrm{ml}$ $(\mathrm{SD}=409)$ of beer on an ordinary beer-drinking occasion; and 305 respondents (excluding 29 respondents who did not drink soju) indicated that they drank an average amount of $357 \mathrm{ml}$ $(\mathrm{SD}=214)$ of regular soju on an ordinary soju-drinking occasion.
We checked to see if there were any significant differences in drinking patterns and alcohol involvement across the five groups of drinkers. Because the Levene's test indicated heterogeneous variances in most of the measures across the five groups, and because the sample sizes were unequal, Welch's F(ANOVA) and the GamesHowell test (post hoc tests) were used to calculate the statistical significance of the group differences. The ANOVAs revealed statistically significant group differences on all measures (for all, Welch's $F>13.00, p<.001$ ). The Games-Howell mean difference test results are reported in Table 1. The domestic beer-preferring group, the imported beer-preferring group, and the soju-preferring group had a relatively higher level of alcohol involvement, whereas the alcopops-preferring group had the lowest level of involvement. The monthly drinking frequencies of all but the alcopops-preferring

〈Table 1〉 Alcohol involvement, drinking frequency, and drinking amount by consumer groups

\begin{tabular}{|c|c|c|c|c|c|c|c|c|c|c|c|c|}
\hline & \multicolumn{12}{|c|}{ Consumer Groups } \\
\hline & \multicolumn{2}{|c|}{$\begin{array}{c}\text { Domestic } \\
\text { beer group }\end{array}$} & \multicolumn{2}{|c|}{$\begin{array}{c}\text { Imported } \\
\text { beer group }\end{array}$} & \multicolumn{2}{|c|}{$\begin{array}{l}\text { Soju } \\
\text { group }\end{array}$} & \multicolumn{2}{|c|}{$\begin{array}{l}\text { Flavored } \\
\text { soju group }\end{array}$} & \multicolumn{2}{|c|}{$\begin{array}{l}\text { Alcopops } \\
\text { group }\end{array}$} & \multicolumn{2}{|c|}{ Total } \\
\hline & $\begin{array}{c}M \\
(S D) \\
\end{array}$ & $n$ & $\begin{array}{c}M \\
(S D) \\
\end{array}$ & $n$ & $\begin{array}{c}M \\
(S D) \\
\end{array}$ & $n$ & $\begin{array}{c}M \\
(S D) \\
\end{array}$ & $n$ & $\begin{array}{c}M \\
(S D) \\
\end{array}$ & $n$ & $\begin{array}{c}M \\
(S D) \\
\end{array}$ & $n$ \\
\hline Involvement & $\begin{array}{c}3.02_{\mathrm{a}, \mathrm{b}} \\
(.99)\end{array}$ & 65 & $\begin{array}{c}3.11_{\mathrm{a}} \\
(1.00)\end{array}$ & 92 & $\begin{array}{l}3.26 \mathrm{a} \\
(.91)\end{array}$ & 61 & $\begin{array}{c}2.61_{b} \\
(1.08)\end{array}$ & 65 & $\begin{array}{l}2.01_{c} \\
(.81)\end{array}$ & 51 & $\begin{array}{c}2.86 \\
(1.05)\end{array}$ & 334 \\
\hline $\begin{array}{l}\text { Frequency } \\
\text { (times) }\end{array}$ & $\begin{array}{l}4.77_{\mathrm{a}} \\
(2.62)\end{array}$ & 65 & $\begin{array}{l}4.65_{a} \\
(2.74)\end{array}$ & 92 & $\begin{array}{c}4.95 \mathrm{a} \\
(2.86)\end{array}$ & 61 & $\begin{array}{c}4.03_{\mathrm{a}} \\
(2.89)\end{array}$ & 65 & $\begin{array}{c}2.71_{b} \\
(1.67)\end{array}$ & 51 & $\begin{array}{c}4.31 \\
(2.72)\end{array}$ & 334 \\
\hline $\begin{array}{c}\text { Amount } \\
\text { (beer; ml) }\end{array}$ & $\begin{array}{c}860_{a} \\
(411)\end{array}$ & 65 & $\begin{array}{c}785 a \\
(383)\end{array}$ & 92 & $\begin{array}{c}949 a \\
(500)\end{array}$ & 47 & $\begin{array}{c}748 \mathrm{a} \\
(374)\end{array}$ & 44 & $\begin{array}{c}521_{b} \\
(229)\end{array}$ & 47 & $\begin{array}{c}780 \\
(409)\end{array}$ & 295 \\
\hline $\begin{array}{l}\text { Amount } \\
\text { (soju; ml) }\end{array}$ & $\begin{array}{c}311_{a} \\
(171)\end{array}$ & 63 & $\begin{array}{c}342_{\mathrm{a}} \\
(187)\end{array}$ & 82 & $\begin{array}{l}509_{b} \\
(211)\end{array}$ & 61 & $\begin{array}{c}377_{\mathrm{a}} \\
(233)\end{array}$ & 60 & $\begin{array}{l}190_{c} \\
(145)\end{array}$ & 39 & $\begin{array}{c}357 \\
(214)\end{array}$ & 305 \\
\hline
\end{tabular}

Note. Values with different subscripts in the same row are statistically different at the .05 level. 
group were similar to each other (4-5 times per month). The alcopops-preferring group had a significantly lower frequency of alcohol consumption (2.7 times per month). When drinking beer, all but the alcopops-preferring group consumed similar amounts of beer (about 2.1-2.7 cans), but the alcopops-preferring group consumed significantly less (1.5 cans of beer). On a typical occasion of drinking soju, the soju-preferring group had the largest amount (11.3 shots), followed by the domestic beerpreferring group, the imported beer-preferring group, and the flavored soju-preferring group, whose drinking amount was not significantly different from each other's (ranging 6.9-8.4 shots). The alcopops-preferring group consumed the least amount of soju (4.2 shots).

\subsection{Correlations}

Correlation analyses were performed to see the relationships between alcohol involvement, drinking frequency, amount, and the consumers' preferences for various drink types. The frequency of drinking, consumption quantity (both beer and soju), and alcohol involvement were all positively correlated with each other $(.39<r<$ $.51 ; p<.05)$. There were also some significant relationships between these variables (involvement, frequency, and amount) and drink type preferences (see Table 2). For example, a higher level of alcohol involvement was significantly associated with an increasing preference for imported beer and soju, and a decreasing preference for flavored soju and alcopops. Also, a higher frequency of drinking was significantly associated with an increasing preference for soju and decreasing preferences for flavored soju and alcopops.

\subsection{Drinking Motives}

To analyze drinking motives, respondents' average drinking motives were first computed. Overall, the grand mean value of the social drinking motive was the highest $(\mathrm{M}=2.71$, $\mathrm{SD}=.78)$ followed by the enhancement motive $(\mathrm{M}=2.22, \mathrm{SD}=.70)$, the conformity

〈Table 2〉 Correlations of alcohol involvement, drinking frequency, amount and drink type preferences

\begin{tabular}{lccccc}
\hline & \multicolumn{5}{c}{ Drink Type } \\
& Domestic beer & Imported beer & Soju & Flavored soju & Alcopops \\
\hline Alcohol involvement & -.11 & $-.14^{* * *}$ & $-.30^{* * *}$ & $.16^{* * *}$ & $.36^{* * *}$ \\
Frequency & -.06 & -.08 & $-.22^{* * *}$ & $.15^{* * *}$ & $.28^{* * *}$ \\
Amount (beer) & $-.19^{* *}$ & -.01 & $-.33^{* *}$ & $.12^{* *}$ & $.33^{* * *}$ \\
Amount (soju) & .07 & .05 & $-.49^{* *}$ & .05 & $.36^{* * *}$ \\
\hline
\end{tabular}

Note. Spearman's correlation coefficients $\left({ }^{*} p<.05\right.$ and $\left.{ }^{* * *} p<.01\right)$ are reported as the preference data are rank-ordered data (i.e., lower values indicate higher preferences). 
motive $(\mathrm{M}=2.07, \mathrm{SD}=.78)$, and the coping motive $(\mathrm{M}=2.03, \mathrm{SD}=.71)$. The degrees of the four drinking motives were significantly different from each other except for the coping and the conformity motives, which were not significantly different from each other (at $p=$ .05). This pattern of results is consistent with some prior research findings (see Kuntsche et al., 2005 for a review) that young people's strongest motive for alcohol consumption tends to be the social motive, followed by the enhancement motive.

We then analyzed consumers' drinking motives for different types of alcoholic beverages. As shown in Table 3, the patterns of drinking motives were not identical for the different types of drinks. The social motive was most strongly associated with domestic beer consumption and most weakly associated with alcopops consumption out of all the types of alcoholic drinks. Similarly, the conformity motive was also most strongly associated with domestic beer consumption and most weakly associated with alcopops consumption. The enhancement motive, on the other hand, was most strongly associated with imported beers and most weakly associated with soju consumption. Last, the coping motive was most strongly associated with domestic beer, imported beer, and soju, but it was most weakly associated with alcopops. The patterns of social motive and conformity motive were similar, in that they were most strongly associated with domestic beer, followed by soju, flavored soju, and imported beer, and most weakly associated with alcopops. In other words, the external reasons (i.e., gaining positive outcomes and avoiding negative outcomes in a social relationship context) appear to be very strongly associated with young adult females' consumption of Korean brand beer, followed by regular soju and flavored soju. Unlike the external reasons, on the other hand, the two

〈Table 3〉 Drinking motives by alcoholic drink types (for all respondents)

\begin{tabular}{|c|c|c|c|c|c|}
\hline & \multicolumn{5}{|c|}{ Drink Type } \\
\hline & Domestic beer & Imported beer & Soju & Flavored soju & Alcopops \\
\hline Coping motive & $\begin{array}{l}2.29^{3} \mathrm{a} \\
(1.03)\end{array}$ & $\begin{array}{l}2.22^{2} \mathrm{a} \\
(1.13) \\
\end{array}$ & $\begin{array}{l}2.22^{2} \mathrm{a} \\
(1.18)\end{array}$ & $\begin{array}{l}1.81^{4} \mathrm{~b} \\
(.97)\end{array}$ & $\begin{array}{l}1.62^{3} \mathrm{c} \\
(.87)\end{array}$ \\
\hline Social motive & $\begin{array}{l}3.20^{1} \mathrm{a} \\
(1.00)\end{array}$ & $\begin{array}{l}2.60^{1} \mathrm{c} \\
(1.12)\end{array}$ & $\begin{array}{l}2.89^{1} \mathrm{~b} \\
(1.12)\end{array}$ & $\begin{array}{l}2.81^{1} \mathrm{~b} \\
(1.23)\end{array}$ & $\begin{array}{l}2.05_{d}^{1} \\
(1.15)\end{array}$ \\
\hline Conformity motive & $\begin{array}{l}2.35^{3} \mathrm{a} \\
(.96)\end{array}$ & $\begin{array}{l}1.96^{3} \mathrm{c} \\
(.92)\end{array}$ & $\begin{array}{l}2.18^{2} \mathrm{~b} \\
(1.02)\end{array}$ & $\begin{array}{l}2.15^{2} \mathrm{~b} \\
(1.09)\end{array}$ & $\begin{array}{l}1.72_{\mathrm{d}}^{2} \\
(.96)\end{array}$ \\
\hline Enhancement motive & $\begin{array}{l}2.53^{2} \mathrm{~b} \\
(1.01)\end{array}$ & $\begin{array}{l}2.67^{1} a \\
(1.14)\end{array}$ & $\begin{array}{c}1.84^{3} \mathrm{~d} \\
(.93)\end{array}$ & $\begin{array}{l}1.98^{3} \mathrm{c} \\
(1.00)\end{array}$ & $\begin{array}{l}2.08^{1} \mathrm{c} \\
(1.08)\end{array}$ \\
\hline
\end{tabular}

Note. All respondents' drinking motives for different drink types. For each drinking motive (i.e., row), the mean values with different subscripts are statistically different at the .05 level. For each drink type (i.e., column), the mean values with different superscripts are statistically different at the .05 level. 
internal reasons (coping and enhancement) did not show similar patterns of association. In addition, when the drinking motive patterns of each drink type were compared, the social drinking motive (external, positive) was the strongest motive for drinking for all types. For imported beer and alcopops, however, the enhancement motive turned out to be as important as the social motive.

Next, each consumer group's drinking motive patterns associated with their preferred type of drink (see Figure 1) were compared. The domestic beer-preferring group, soju-preferring group, and flavored soju-preferring group consumed their most preferred type of drink for social reasons more than for other types of reasons. On the other hand, for those who preferred imported beers, the enhancement motive was the strongest motive (i.e., stronger than the social motive). Unlike the other groups, the soju-preferring group's coping motive for consuming soju was significantly stronger than their conformity motive. For the flavored-sojupreferring group, the social motive was the strongest, but the other three types of motives were not significantly different from each other.

\subsection{Drink Choices by Consumption Location}

As shown in Table 4, imported beer (43.7\%) was the most frequently consumed type when respondents purchased alcohol to drink at home. When drinking at a restaurant, they had domestic beer most frequently (37.1\%), followed by soju (27.5\%). When drinking at a bar, they consumed soju (32.9\%) most frequently, followed by flavored soju (27.5\%) and domestic

〈Figure 1〉 Drinking motives associated with preferred type of alcoholic drink

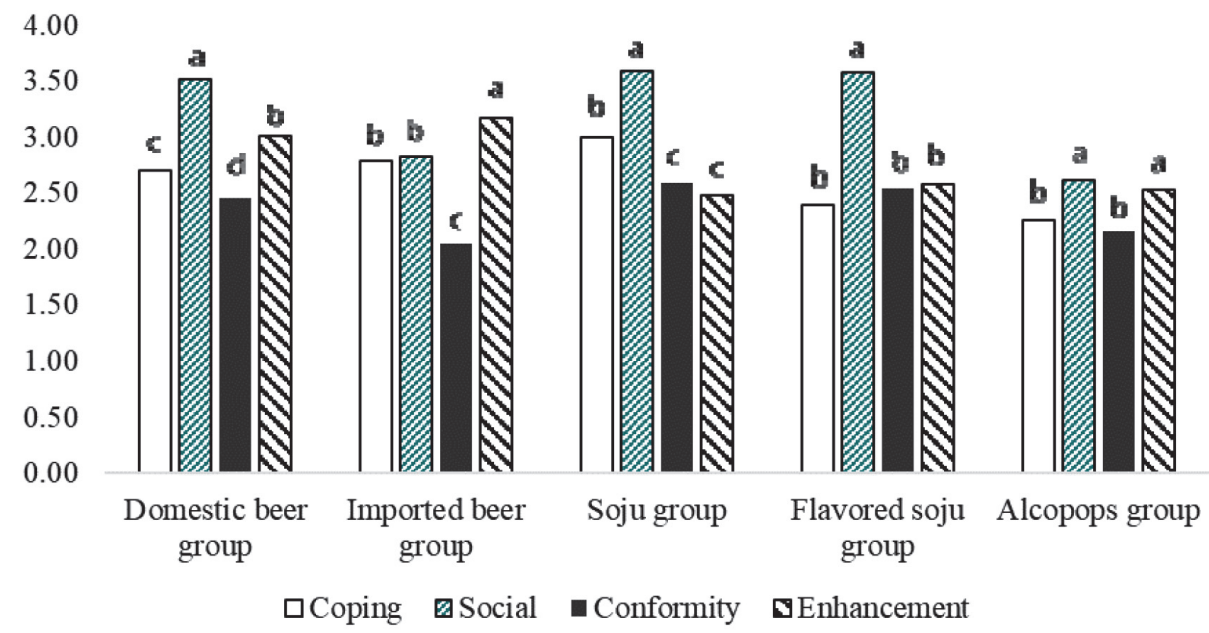

Note: Within each cluster (consumer group), the mean values with different letters are different at $p<.06$. 
beer $(23.4 \%)$. When respondents purchased alcoholic drinks at a convenience store, imported beer $(50.6 \%)$ was the most frequently purchased, followed by alcopops (25.7\%).

We then checked to see if, and how, the patterns of drink-type choices by locations differed for different groups of consumers. When drinking at home, the domestic beerpreferring group, the imported beer-preferring group, and the alcopops-preferring group consumed their preferred type of drink most frequently (domestic beer, 46.2\%; imported beer, 78.3\%; alcopops, 74.5\%). On the other hand, many soju-preferring consumers indicated that they consumed beer (imported beer, 42.6\%; domestic beer, 31.1\%) most frequently when drinking at home. The flavored soju-preferring group's two most frequently consumed drinks at home were alcopops (30.8\%) and imported beer $(29.2 \%)$. When drinking at a restaurant, domestic beer and soju were the two most frequently consumed drinks for the domestic beer-preferring group $(78.5 \%$ for domestic beer and soju combined), the imported beer-preferring group (68.4\%), and the soju-preferring group (91.8\%). However, the flavored soju-preferring group consumed flavored soju (52.3\%) most frequently when drinking at a restaurant. The alcopops-preferring group most frequently consumed domestic beer $(41.2 \%)$ at a restaurant, followed by flavored soju (15.7\%) and alcopops (15.7\%). The respondents' drink-choice patterns when drinking at a bar were similar to their choice patterns associated with restaurants, except that the alcopops-preferring group consumed flavored soju (33.3\%) most frequently, followed by domestic beer (23.5\%), when drinking at a bar. When purchasing at a convenience store, the top two most frequently chosen drink types of the domestic beer-preferring group, the imported beer-preferring group, and the soju-preferring group were imported beer $(59.5 \%$ on average) and domestic beer (21.2\%), but the flavored soju-preferring group and the alcopops-preferring group's top two choices were alcopops (52.4\%) and imported beer (29.1\%).

〈Table 4〉 Choice of alcoholic drinks by location of drinking (or purchase)

\begin{tabular}{|c|c|c|c|c|c|c|c|}
\hline & $\begin{array}{c}\text { Domestic } \\
\text { beer }\end{array}$ & $\begin{array}{c}\text { Imported } \\
\text { beer }\end{array}$ & Soju & $\begin{array}{c}\text { Flavored } \\
\text { soju }\end{array}$ & Alcopops & Other & Total \\
\hline At Home & $\begin{array}{c}67 \\
(20.1 \%)\end{array}$ & $\begin{array}{c}146 \\
(43.7 \%)\end{array}$ & $\begin{array}{c}11 \\
(3.3 \%)\end{array}$ & $\begin{array}{c}9 \\
(2.7 \%)\end{array}$ & $\begin{array}{c}73 \\
(21.9 \%)\end{array}$ & $\begin{array}{c}28 \\
(8.4 \%)\end{array}$ & 334 \\
\hline Restaurant & $\begin{array}{c}124 \\
(37.1 \%)\end{array}$ & $\begin{array}{c}32 \\
(9.6 \%)\end{array}$ & $\begin{array}{c}92 \\
(27.5 \%)\end{array}$ & $\begin{array}{c}63 \\
(18.9 \%)\end{array}$ & $\begin{array}{c}13 \\
(3.9 \%)\end{array}$ & $\begin{array}{c}10 \\
(3.0 \%)\end{array}$ & 334 \\
\hline Bar & $\begin{array}{c}78 \\
(23.4 \%)\end{array}$ & $\begin{array}{c}22 \\
(6.6 \%)\end{array}$ & $\begin{array}{c}110 \\
(32.9 \%)\end{array}$ & $\begin{array}{c}92 \\
(27.5 \%)\end{array}$ & $\begin{array}{c}4 \\
(1.2 \%) \\
\end{array}$ & $\begin{array}{c}28 \\
(8.4 \%) \\
\end{array}$ & 334 \\
\hline Convenience Store & $\begin{array}{c}53 \\
(15.9 \%)\end{array}$ & $\begin{array}{c}169 \\
(50.6 \%)\end{array}$ & $\begin{array}{c}7 \\
(2.1 \%)\end{array}$ & $\begin{array}{c}12 \\
(3.6 \%)\end{array}$ & $\begin{array}{c}86 \\
(25.7 \%)\end{array}$ & $\begin{array}{c}7 \\
(2.1 \%)\end{array}$ & 334 \\
\hline
\end{tabular}




\subsection{Companions and Drink Choice}

Last, respondents' drink choice patterns in terms of drinking companions were analyzed. For each of the three drinking occasions (drinking alone, with friends, and with family), participants indicated how frequently they consumed domestic beer, imported beer, soju, flavored soju, and alcopops on a 5 -point scale $(1=$ almost never; $5=$ almost always). As shown in Table 5 , imported beer was the most frequently consumed type of drink when the respondents drank alone. When drinking with others, they frequently had domestic beer, soju, and flavored soju. Specifically, they consumed domestic beer most frequently when drinking with family, and consumed domestic beer, soju, and flavored soju most frequently when drinking with friends.

Next, each consumer group's drink-choice patterns for different drinking contexts (companion types) were analyzed. Table 6 shows the results. To summarize the overall patterns, imported beer tends to have a strong appeal to most of the respondents when they drink alone. When drinking with friends, many people tend to frequently choose their personally preferred drink type in addition to domestic beer. When drinking with family, both domestic beer and imported beer are frequently consumed in addition to the consumer's personally preferred drink type.

\section{Conclusion and Discussion}

Many food-consumer studies have investigated people's alcohol-consumption patterns, consumption motives, preferences for various alcoholic drink types, important product attributes influencing brand or product choices, and various sociodemographic and psychological factors that are associated with alcohol consumption (e.g., Cardello et al., 2016: Corduas, Cinquanta, \& Ievoli, 2013; Jaeger et al., 2017; Muggah \& McSweeney, 2017; Thach \& Olsen, 2006). However, the research that investigated differential

〈Table 5〉 The means and standard deviations of alcohol consumption frequency ratings by drink type and context (for all respondents)

\begin{tabular}{lccccc}
\hline & Domestic beer & Imported beer & Soju & Flavored soju & Alcopops \\
\hline Drinking Alone & $2.20_{\mathrm{a}}$ & $2.64_{\mathrm{b}}$ & $1.38_{\mathrm{c}}$ & $1.52_{\mathrm{d}}$ & $2.23_{\mathrm{a}}$ \\
& $(1.21)$ & $(1.38)$ & $(0.73)$ & $(0.95)$ & $(1.32)$ \\
With Friends & $3.17_{\mathrm{a}}$ & $2.83_{\mathrm{b}}$ & $3.02_{\mathrm{a}}$ & $3.03_{\mathrm{a}}$ & $2.18_{\mathrm{c}}$ \\
& $(1.19)$ & $(1.25)$ & $(1.25)$ & $(1.32)$ & $(1.25)$ \\
With Family & $2.56_{\mathrm{a}}$ & $2.41_{\mathrm{b}}$ & $1.90_{\mathrm{c}}$ & $1.69_{\mathrm{d}}$ & $1.71_{\mathrm{d}}$ \\
& $(1.26)$ & $(1.29)$ & $(1.10)$ & $(1.05)$ & $(1.11)$ \\
\hline
\end{tabular}

Note. For each drinking context (i.e., row), the mean values with different subscripts are statistically different at the .05 level. 
〈Table 6〉 Each consumer group's means and standard deviations of alcohol consumption frequency ratings by drink type and context

\begin{tabular}{|c|c|c|c|c|c|c|c|}
\hline & & & $\begin{array}{c}\text { Domestic } \\
\text { beer }\end{array}$ & $\begin{array}{c}\text { Imported } \\
\text { beer }\end{array}$ & Soju & $\begin{array}{c}\text { Flavored } \\
\text { soju }\end{array}$ & Alcopop \\
\hline \multirow{5}{*}{$\begin{array}{l}\text { "Drinking } \\
\text { alone" }\end{array}$} & \multirow{5}{*}{$\begin{array}{l}\text { Consumer } \\
\text { Groups }\end{array}$} & $\mathrm{DBG}$ & $\begin{array}{c}2.83_{\mathrm{a}} \\
(1.22)\end{array}$ & $\begin{array}{c}2.68_{a} \\
(1.32)\end{array}$ & $\begin{array}{l}1.37_{\mathrm{c}} \\
(.63)\end{array}$ & $\begin{array}{l}1.60_{c} \\
(.86)\end{array}$ & $\begin{array}{l}2.18 \mathrm{~b} \\
(1.24)\end{array}$ \\
\hline & & IBG & $\begin{array}{c}2.47_{\mathrm{b}} \\
(1.29)\end{array}$ & $\begin{array}{c}3.52_{a} \\
(1.31)\end{array}$ & $\begin{array}{l}1.26_{\mathrm{d}} \\
(.59)\end{array}$ & $\begin{array}{l}1.33_{\mathrm{d}} \\
(.79)\end{array}$ & $\begin{array}{c}2.05_{c} \\
(1.34)\end{array}$ \\
\hline & & $\mathrm{SG}$ & $\begin{array}{c}1.93_{\mathrm{b}} \\
(1.12)\end{array}$ & $\begin{array}{c}2.48 \mathrm{a} \\
(1.29)\end{array}$ & $\begin{array}{l}1.61_{\mathrm{b}} \\
(.92)\end{array}$ & $\begin{array}{l}1.36_{\mathrm{c}} \\
(.71)\end{array}$ & $\begin{array}{c}1.93_{\mathrm{b}} \\
(1.26)\end{array}$ \\
\hline & & FSG & $\begin{array}{l}1.69_{\mathrm{a}, \mathrm{b}} \\
(1.00)\end{array}$ & $\begin{array}{l}1.92_{\mathrm{c}, \mathrm{d}} \\
(1.15)\end{array}$ & $\begin{array}{l}1.52 \mathrm{a} \\
(.90)\end{array}$ & $\begin{array}{l}1.77_{\mathrm{b}, \mathrm{c}} \\
(1.20)\end{array}$ & $\begin{array}{l}2.18 \mathrm{~d} \\
(1.22)\end{array}$ \\
\hline & & $\mathrm{AG}$ & $\begin{array}{c}1.90_{\mathrm{a}, \mathrm{b}} \\
(.90) \\
\end{array}$ & $\begin{array}{l}2.10_{a} \\
(1.10) \\
\end{array}$ & $\begin{array}{l}1.16_{\mathrm{c}} \\
(.46) \\
\end{array}$ & $\begin{array}{l}1.67_{\mathrm{b}} \\
(1.14) \\
\end{array}$ & $\begin{array}{l}3.02 \mathrm{~d} \\
(1.33) \\
\end{array}$ \\
\hline \multirow{5}{*}{$\begin{array}{l}\text { "Drinking with } \\
\text { friends" }\end{array}$} & \multirow{5}{*}{$\begin{array}{l}\text { Consumer } \\
\text { Groups }\end{array}$} & DBG & $\begin{array}{l}3.65 \mathrm{a} \\
(.99)\end{array}$ & $\begin{array}{l}2.91_{\mathrm{b}} \\
(1.17)\end{array}$ & $\begin{array}{c}3.11_{b} \\
(1.00)\end{array}$ & $\begin{array}{c}3.02_{b} \\
(1.19)\end{array}$ & $\begin{array}{c}2.02_{\mathrm{c}} \\
(1.02)\end{array}$ \\
\hline & & IBG & $\begin{array}{c}3.22_{\mathrm{a}} \\
(1.18)\end{array}$ & $\begin{array}{c}3.30 \mathrm{a} \\
(1.26)\end{array}$ & $\begin{array}{l}2.93_{\mathrm{b}} \\
(1.18)\end{array}$ & $\begin{array}{l}2.77_{b} \\
(1.35)\end{array}$ & $\begin{array}{c}2.05_{c} \\
(1.29)\end{array}$ \\
\hline & & $\mathrm{SG}$ & $\begin{array}{c}3.15_{\mathrm{a}} \\
(1.15)\end{array}$ & $\begin{array}{c}2.52_{b} \\
(1.12)\end{array}$ & $\begin{array}{c}3.87_{c} \\
(1.06)\end{array}$ & $\begin{array}{l}2.61_{b} \\
(1.36)\end{array}$ & $\begin{array}{l}2.07_{d} \\
(1.22)\end{array}$ \\
\hline & & FSG & $\begin{array}{l}2.75_{\mathrm{a}} \\
(1.24)\end{array}$ & $\begin{array}{l}2.49_{\mathrm{a}, \mathrm{c}} \\
(1.29)\end{array}$ & $\begin{array}{l}2.85 \mathrm{a} \\
(1.33)\end{array}$ & $\begin{array}{c}3.86 \mathrm{~b} \\
(1.06)\end{array}$ & $\begin{array}{l}2.22_{\mathrm{c}} \\
(1.21)\end{array}$ \\
\hline & & $\mathrm{AG}^{*}$ & $\begin{array}{c}3.04_{a} \\
(1.22)\end{array}$ & $\begin{array}{c}2.67_{\mathrm{b}} \\
(1.16)\end{array}$ & $\begin{array}{l}2.29_{c} \\
(1.19)\end{array}$ & $\begin{array}{l}2.94_{a, b} \\
(1.24)\end{array}$ & $\begin{array}{l}2.71_{\mathrm{b}, \mathrm{c}} \\
(1.40)\end{array}$ \\
\hline \multirow{5}{*}{$\begin{array}{l}\text { "Drinking } \\
\text { with family" }\end{array}$} & \multirow{5}{*}{$\begin{array}{l}\text { Consumer } \\
\text { Groups }\end{array}$} & $\mathrm{DBG}$ & $\begin{array}{c}2.91_{\mathrm{a}} \\
(1.30)\end{array}$ & $\begin{array}{l}2.51_{b} \\
(1.13)\end{array}$ & $\begin{array}{l}1.80_{c} \\
(1.03)\end{array}$ & $\begin{array}{l}1.58 \mathrm{~d} \\
(.90)\end{array}$ & $\begin{array}{l}1.49_{\mathrm{d}} \\
(.85)\end{array}$ \\
\hline & & IBG & $\begin{array}{l}2.76 \mathrm{a} \\
(1.28)\end{array}$ & $\begin{array}{l}2.97 \mathrm{a} \\
(1.40)\end{array}$ & $\begin{array}{l}1.91_{b} \\
(1.12)\end{array}$ & $\begin{array}{l}1.70_{b} \\
(1.10)\end{array}$ & $\begin{array}{l}1.70_{\mathrm{b}} \\
(1.05)\end{array}$ \\
\hline & & $\mathrm{SG}$ & $\begin{array}{c}2.57_{\mathrm{a}} \\
(1.23)\end{array}$ & $\begin{array}{l}2.15 \mathrm{~b} \\
(1.24)\end{array}$ & $\begin{array}{l}2.54 \mathrm{a} \\
(1.22)\end{array}$ & $\begin{array}{l}1.66_{c} \\
(.96)\end{array}$ & $\begin{array}{c}1.57_{\mathrm{c}} \\
(1.13)\end{array}$ \\
\hline & & FSG & $\begin{array}{c}2.09 \mathrm{a} \\
(1.13)\end{array}$ & $\begin{array}{l}2.03_{\mathrm{a}, \mathrm{b}} \\
(1.13)\end{array}$ & $\begin{array}{l}1.72_{\mathrm{b}} \\
(.99)\end{array}$ & $\begin{array}{l}1.82_{a, b} \\
(1.19)\end{array}$ & $\begin{array}{c}1.71_{\mathrm{b}} \\
(1.09)\end{array}$ \\
\hline & & $\mathrm{AG}$ & $\begin{array}{c}2.33 \mathrm{a} \\
(1.18)\end{array}$ & $\begin{array}{c}2.08 \mathrm{a} \\
(1.16)\end{array}$ & $\begin{array}{l}1.45 \mathrm{~b} \\
(.76)\end{array}$ & $\begin{array}{l}1.69 \mathrm{~b} \\
(1.07)\end{array}$ & $\begin{array}{l}2.20 \mathrm{a} \\
(1.37)\end{array}$ \\
\hline
\end{tabular}

Note. For each row, the mean values with different subscripts are statistically different at the .05 level. $\left(^{*}:\right.$ different at the .06 level). DBG (domestic beer-preferring group), IBG (imported beer-preferring group), SG (soju-preferring group), FSG (flavored soju-preferring group), AG (alcopops-preferring group).

patterns of drinking motivations associated with different types of alcoholic drinks is very limited. Also, the prior studies that directly explored psychological motives for alcoholic-drink consumption have been conducted mostly in Western countries (e.g., Bruwer \& Li, 2007; Charters \& Pettigrew, 
2008; Gómez-Corona et al., 2016; Ritchie, 2007: Somogyi et al., 2011). Addressing these limitations, this study investigated young adult female consumers' psychological motives (e.g., coping, social, conformity, and enhancement motives) for drinking different types of alcoholic beverages in Korea, one of the major geographic segments in the global alcoholic-beverage market.

The major findings and implications of this study can be summarized as follows. First, when specific drink types were not taken into consideration, the social motive was generally the strongest drinking motive of the young adult female drinkers in Korea, followed by the enhancement motive. This pattern of results is consistent with prior research findings regarding young consumers' drinking motives reported in Western countries (see Kuntsche et al., 2005). However, there are also differences. For example, in Loose and Acier (2017), young French women's coping motive for drinking was found to be stronger than the conformity motive. Similarly, Lyvers et al. (2010) reported that young Australian drinkers' coping motive for drinking was stronger than their conformity motive. The authors also reported that coping and enhancement motives were strongly related to both alcohol consumption and alcohol-related problems, while conformity motives were unrelated. In our study, the strength of the coping motive and that of the conformity motive were not significantly different from each other in general. More important, we found that the relative strength of the conformity motive varied depending on specific drink types (e.g., beer vs. soju).

Second, when the survey participants were grouped together on the basis of their most frequently consumed type of alcoholic beverage, their alcohol consumption patterns in terms of general drinking frequency and beer consumption amount were similar, except for the alcopopspreferring consumers, who generally consumed alcoholic beverages significantly less (both in frequency and amount) than did the other groups. The alcopops-preferring group also showed the lowest level of alcohol involvement. Hence, it appears that, in the Korean alcoholic-drinks market, alcopops have a strong appeal to young female consumers who are relatively low on alcohol involvement and want low-alcoholcontent drinks. For the psychological drinking motives, both the social motive and the enhancement motive were relatively strong for this group's alcopops consumption, but this group appears to enjoy drinking alcopops most frequently when drinking alone and at home. The flavored soju-preferring group showed the second lowest level of alcohol involvement. The other groups who enjoyed the typical alcoholic drinks (beer or regular soju) were similar to each other in their level of alcohol involvement, general frequency of alcohol consumption, and beer consumption amount.

There were also some significant differences between the consumers' alcohol consumption motives in terms of the different types of 
alcoholic drinks. In a general drinking context (i.e., when specific drink types are ignored), the externally positive, social motive was found to be the strongest psychological motive for drinking. However, when specific drink-types were taken into account, the internally positive, enhancement motive turned out to be as important as the social motive for young adult female consumers' imported beer and alcopops consumption. In addition, for the imported beerpreferring group, the enhancement motive worked more strongly than did the social motive when they drank imported beers. In contrast, the domestic beer-preferring group was found to consume domestic beers primarily for the social motive. ${ }^{1)}$ These results are also in line with the findings on the alcohol-consumption contexts (location and companion), in that respondents' consumption of imported beer was strongly associated with "purchasing at convenience stores', 'drinking at home', and 'drinking alone'. Unlike the imported-beer consumption pattern, respondents' consumption of domestic beer was more strongly associated with social drinking, such as 'drinking with friends and family' and 'drinking at restaurants and bars'. Like domesticbeer consumption, respondents' consumption of regular soju and flavored soju was also strongly associated with social contexts (e.g., drinking with others), as is consistent with the patterns of drinking motives, in that social motives were strongly associated with consuming both regular and flavored soju.

Theoretically, this study contributes to the literature on alcohol consumption by demonstrating that the relative strength/weakness of coping, social, conformity, and enhancement motives behind alcohol consumption can differ not only for different alcoholic drink types, but also for different drinker segments for the same type of drinks. This study segmented consumers based on a simple behavioral variable ("what the consumer most frequently drinks') that has not been commonly used in the relevant literature on segmentation in the alcoholic beverages domain and found that consumers' psychological motives for drinking the same type of alcoholic beverage can differ depending

1) The differential patterns of association are also reflected in the significant interaction between beer type (domestic vs. imported beer) and motive type (enhancement vs. social) found in a supplementary repeated-measures ANOVA conducted on each beer group's drinking motives. For the domestic beer-preferring group, the two-way interaction between beer type and motive type was significant $(F(1,64)=25.12, p<.001)$, and the subsequent simple-effect analysis showed a significant simple effect of motive such that the social motive was significantly stronger than the enhancement motive for drinking domestic beer $(F(1,64)=21.82, p<.001)$, but not for drinking imported beer $(F(1,64)=1.86, p>15)$. For the imported beer-preferring group, on the contrary, the subsequent simple-effect analysis following a repeated-measure $\operatorname{ANOVA}(F(1,91)=46.20, p<.001$ for the two-way interaction effect) revealed two simple effects such that the social motive was stronger than the enhancement motive when drinking domestic beer $(F(1,91)=32.66, p<.001)$, whereas the enhancement motive was stronger than the social motive when drinking imported beer $(F(1,91)=6.83, p<.05)$. 
on what the consumer most frequently consumes. For beverage marketing, our findings provide managerial insights by implying that emphasizing or reinforcing the psychological benefits and related product attributes that are strongly associated with the specific beverage type would help build effective product development, positioning, and marketing communication strategies. For instance, because the enhancement motive appears to be important in young female Korean consumers' decisions on imported beer and alcopops consumption, marketers can aim at improving consumers' personal hedonic experiences by providing better tastes, various flavors to choose from, or an aesthetically pleasing packaging design. On the other hand, because the social motive plays a more important role in domestic beer and soju consumption, domestic beer and soju brands would be able to better satisfy consumer needs for obtaining social acceptance and improving interpersonal relationships by reinforcing the image of the product as a social enhancer and emphasizing the contextual appropriateness of choosing domestic beer or soju over other types of alcoholic drinks when drinking to celebrate or have a good time with others. This does not necessarily mean that they do not need to improve the sensory attributes (e.g., taste, aroma) of such alcoholic drinks. Since a hedonic activity can be experienced alone or shared with others (Raghunathan \& Corfman, 2006), the same sensory attribute can also be presented in different frames (e.g.,
"Enjoy the great taste for yourself!" vs. "Enjoy the great taste with your loved ones!") depending on the brand's desired positioning strategy. In addition, although this study was not about health, our findings can also provide implications for health promotion campaigns in reducing high-risk or problematic drinking. For example, because people's drinking motivations can differ for different types of alcoholic beverages, not only identifying which specific type of alcoholic drink is strongly associated with problematic drinking behaviors but also assessing alcoholicbeverage type-specific drinking motives may be necessary for designing a health promotion campaign in a more effective manner.

Although this research uncovered some meaningful insights about consumers' psychological motivation for consuming various types of alcoholic beverages, several limitations of this study should be noted. The first pertains to sample size and composition. This study relied on a relatively small sample which only consisted of university students. Although it is not very uncommon in the literature to address young adults' drinking behaviors or motivations relying on university student samples (e.g., Li et al., 2011; Stewart \& Devine, 2000), the generalizability of the study findings regarding drinking motives certainly awaits replication in more diverse and representative samples (e.g., a larger sample from a wider range of age and socioeconomic backgrounds). It would be also meaningful to investigate both male and female consumers to 
see whether and what gender differences may exist in consumers' beverage-type-specific consumption motivations. Second, although this study focused on investigating whether, and what, differences exist in drinking motives for consuming different types of alcoholic beverages, it did not consider what makes or contributes to such differences in drink-typespecific consumption motives. Hence, future research can fruitfully explore why such differences exist. Along that line, we can also investigate consumers' cognitive and affective responses toward various types of alcoholic beverages (e.g., Chrysochou, 2014; Silva et al., 2016) and see how consumers' perceptions of and concepts about of different types of alcoholic beverages are linked to their psychological motives for consumption.

〈Received July 19. 2018〉 〈Accepted October 11. 2018〉

\section{References}

Balestrini, P., \& Gamble, P. (2006). Countryof-origin effects on Chinese wine consumers. British Food Journal, 108(5), 396-412.

Bruwer, J., Chrysochou, P., \& Lesschaeve, I. (2017). Consumer involvement and knowledge influence on wine choice cue utilisation. British Food Journal, 119(4), 830-844.

Bruwer, J., \& Li, E. (2007). Wine-related lifestyle
(WRL) market segmentation: Demographic and behavioural factors. Journal of Wine Research, 18(1), 19-34.

Çakar, U., \& Kim, H. (2015). Korea's drinking culture: When an organizational socialization tool threatens workplace well-being. Turkish Journal of Business Ethics, 8(2), 289-309. Cardello, A. V., Pineau, B., Paisley, A. G., Roigard, C. M., Chheang, S. L., Guo, L. F., Hedderley, D. I., \& Jaeger, S. R. (2016). Cognitive and emotional differentiators for beer: An exploratory study focusing on "uniqueness". Food Quality and Preference, 54, 23-38.

Charters, S., \& Pettigrew, S. (2008). Why do people drink wine? A consumer-focused exploration. Journal of Food Products Marketing, 14(3), 13-32.

Chrysochou, P. (2014). Drink to get drunk or stay healthy? Exploring consumers' perceptions, motives and preferences for light beer. Food Quality and Preference, 31, 156-163. Cooper, M. L. (1994). Motivations for alcohol use among adolescents: Development and validation of a four-factor model. Psychological Assessment, 6(2), 117.

Corduas, M., Cinquanta, L., \& Ievoli, C. (2013). The importance of wine attributes for purchase decisions: A study of Italian consumers' perception. Food Quality and Preference, 28(2), 407-418.

Cox, W. M., \& Klinger, E. (1988). A motivational model of alcohol use. Journal of Abnormal 
Psychology, 97(2), 168.

Fabbrizzi, S., Marinelli, N., Menghini, S., \& Casini, L. (2017). Why do you drink? A means-end approach to the motivations of young alcohol consumers. British Food Journal, 119(8), 1854-1869.

Global Agriculture Information Network (2018). Republic of Korea: Beer Market Report. GAIN Report No. KS1806. United States Department of Agriculture (USDA) Foreign Agricultural Service.

Gómez-Corona, C., Escalona-Buendía, H. B., García, M., Chollet, S., \& Valentin, D. (2016). Craft vs. industrial: Habits, attitudes and motivations towards beer consumption in Mexico. Appetite, 96, 358-367.

Graziano, F., Bina, M., Giannotta, F., \& Ciairano, S. (2012). Drinking motives and alcoholic beverage preferences among Italian adolescents. Journal of Adolescence, 35(4), 823-831.

Jackson, J. (2017, January 6). Table for one, please. The Korea Herald. Retrieved from http://www.koreaherald.com/view.php? $\mathrm{ud}=20170106000634$

Jaeger, S. R., Cardello, A. V., Chheang, S. L., Beresford, M. K., Hedderley, D. I., \& Pineau, B. (2017). Holistic and consumercentric assessment of beer: A multimeasurement approach. Food Research International, 99, 287-297.

Jang, J. (2017, April 22). Breweries diversify with weaker beers, and not-beer beers. Korea Joongang Daily. Retrieved from http://koreajoongangdaily.joins.com/ news /article/article.aspx? aid $=3032538$ Jang, R. (2015, September 10). Women in heavy-drinking S. Korea fuel demand for lighter booze. Reuters. Retrieved from https://www.reuters.com/article/southkorea -spirits/women-in-heavy-drinking-s-korea -fuel-demand-for-lighter-booze-idUSL4 N11D2CA20150910

Kim, D. (2018, February 7). Local beer makers struggle amid imported beer boom. The Korea Herald. Retrieved from http://www. koreaherald.com/view.php?ud $=201802070$ 00576

Kim, Y., \& Hong, O. (2012). Characteristics and factors of alcohol consumption among Korean male workers. Drugs: Education, Prevention and Policy, 19(4), 339-345.

Kim, D., \& Rhee, J. (2014). A study on the mediating effects of alcohol drinking expectancies of employee between drinking motives and drinking culture at the workplace. Journal of Organization and Management, 38(4), 1-26.

Korea Agro-Fisheries \& Food Trade Corporation (2016). The market trend of processed food segmentation - beverages market. Available from http://www.atfis.or.kr

Korea Customs Service (2018). Trade Statistics. Available from https://unipass.customs.go.kr Kuntsche, E., Knibbe, R., Gmel, G., \& Engels, R. (2005). Why do young people drink? A review of drinking motives. Clinical Psychology 
Review, 25(7), 841-861.

Kuntsche, E., Knibbe, R., Gmel, G., \& Engels, R. (2006). 'I drink spirits to get drunk and block out my problems..' Beverage preference, drinking motives and alcohol use in adolescence. Alcohol and Alcoholism, 41(5), 566-573.

Li, J. G., Jia, J. R., Taylor, D., Bruwer, J., \& Li, E. (2011). The wine drinking behaviour of young adults: An exploratory study in China. British Food Journal, 113(10), 13051317.

Loose, T., \& Acier, D. (2017). Drinking motives and alcohol consumption behaviors among young French people. Addictive Behaviors, 72, 120-125.

Lyvers, M., Hasking, P., Hani, R., Rhodes, M., \& Trew, E. (2010). Drinking motives, drinking restraint and drinking behaviour among young adults. Addictive Behaviors, 35(2), 116-122.

Marinelli, N., Fabbrizzi, S., Sottini, V. A., Sacchelli, S., Bernetti, I., \& Menghini, S. (2014). Generation Y, wine and alcohol. A semantic differential approach to consumption analysis in Tuscany. Appetite, 75, 117-127.

Mosher, J. F., \& Johnsson, D. (2005). Flavored alcoholic beverages: An international marketing campaign that targets youth. Journal of Public Health Policy, 26(3), 326-342.

Muggah, E. M., \& McSweeney, M. B. (2017). Females' attitude and preference for beer: A conjoint analysis study. International Journal of Food Science \& Technology, 52
(3), 808-816.

Olsen, J., Atkin, T., \& Thach, L. (2016). Marketing by what matters: Using Schwartz's theory of basic values to identify wine consumer segments. In Bruwer, J., Lockshin, L., Corsi, A., Cohen, J., \& Hirche, M. (Eds.) Wine Business Research That Matters: Proceedings of the 9th Academy of Wine Business Research Conference (pp. 301-312). Adelaide, Australia: Ehrenberg-Bass Institute for Marketing Science.

Palma, D., Cornejo, C., Ortuzar, J., Rizzi, L., \& Casaubon, G. (2014, June). Tell me why you like to drink wine: Drinking motivations as a basis for market segmentation. Paper presented at the 8th International Conference of the Academy of Wine Business Research. Pomarici, E., Lerro, M., Chrysochou, P., Vecchio, R., \& Krystallis, A. (2017). One size does (obviously not) fit all: Using product attributes for wine market segmentation. Wine Economics and Policy, 6(2), 98-106. Raghunathan, R., \& Corfman, K. (2006). Is happiness shared doubled and sadness shared halved? Social influence on enjoyment of hedonic experiences. Journal of Marketing Research, 43(3), 386-394.

Ritchie, C. (2007). Beyond drinking: The role of wine in the life of the UK consumer. International Journal of Consumer Studies, 31(5), 534-540.

Schwartz, S. H. (2012). An overview of the Schwartz theory of basic values. Online 
Readings in Psychology and Culture, 2(1). https://doi.org/10.9707/2307-0919.1116

Shin, H. W., \& Han, S. Y. (1999). A preliminary study for developing drinking motives scale. Korean Journal of Psychology: Social Issues, 5(1), 77-92.

Silva, A. P., Jager, G., Van Bommel, R., Van Zyl, H., Voss, H. P., Hogg, T., Pintado, M., \& De Graaf, C. (2016). Functional or emotional? How Dutch and Portuguese conceptualise beer, wine and non-alcoholic beer consumption. Food Quality and Preference, 49, 54-65.

Silva, A. P., Jager, G., Van Zyl, H., Voss, H. P., Pintado, M., Hogg, T., \& De Graaf, C. (2017). Cheers, Proost, Saúde: Cultural, contextual and psychological factors of wine and beer consumption in Portugal and in the Netherlands. Critical Reviews in Food Science and Nutrition, 57(7), 1340-1349.

Sohn, J. (2016, January 7). Beer emerging as Korea's top-selling alcohol. The Korea Herald. Retrieved from http://www.koreaherald. com $/$ view.php?ud $=20160107001091$

Somogyi, S., Li, E., Johnson, T., Bruwer, J., \& Bastian, S. (2011). The underlying motivations of Chinese wine consumer behaviour. Asia Pacific Journal of Marketing and Logistics, 23(4), 473-485.

Stewart, S. H., \& Devine, H. (2000). Relations between personality and drinking motives in young adults. Personality and Individual Differences, 29(3), 495-511.

Thach, E. C., \& Olsen, J. E. (2006). Market segment analysis to target young adult wine drinkers. Agribusiness, 22(3), 307-322. Thong, N. T., Thanh, B. Q., Solgaard, H. S., \& Yang, Y. (2017). The role of packaging format, alcohol level and brand in consumer's choice of beer: A best-worst scaling multiprofile approach. Food Quality and Preference, 65, 92-100.

World Health Organization. Global status report on alcohol and health. (2014). http://www. who.int/substance_abuse/publications/ alcohol/en/ Accessed 30 June 2018.

Yang, N. M. (2015). Development and validation of the Korean version of college life alcohol salience scale. The Korean Journal of Counseling and Psychotherapy, 27(1), 4161.

Zaichkowsky, J. L. (1985). Measuring the involvement construct. Journal of Consumer Research, 12(3), 341-352. 